\title{
ENTRE ESCILA Y CARIBDIS: LA DIÁSPORA VASCA EN ARGENTINA DURANTE LA DICTADURA
}

\section{BETWEEN SCYLLA AND CHARYBDIS: THE BASQUE DIASPORA IN ARGENTINA DURING THE DICTATORSHIP}

\author{
Maria Eugenia Cruset ${ }^{1 *}$
}

\begin{abstract}
RESUMEN
Al conjunto de inmigrantes que se asocian para conseguir objetivos propios y que tienen una participación de carácter político en destino como en origen es una Diáspora. Estas personas forman parte, por partida doble, de la sociedad civil y en ella se desenvuelven. La gran pregunta es:¿Qué es lo que hace eficiente a un grupo de emigrados para concretar sus objetivos?

En este trabajo intentamos justamente analizar este tema que entendemos como una interrelación entre características propias- liderazgo, número y compromiso de los miembros, asimilación a la sociedad de acogida, etc- y el contexto en el que se desenvuelven. Y, en este sentido, nos preguntamos que posibilidades de éxito pueden tener en situaciones límites de violencia y falta de libertad. Para esto estudiaremos la Diáspora vasca en Argentina durante la última dictadura (19176-1983).
\end{abstract}

Palabras clave: Diáspora-sociedad civil-dictadura-inmigración

\begin{abstract}
The group of immigrants who associate to achieve their own objectives and who have a political participation in destination as well as in origin is a Diaspora. These people are doubly part of the civil society and they develop in it. The big question is: what makes a group of emigrants efficient in order to achieve their objectives? Here, in this paper, we try to think about it, especially in troubled moments like a dictatorship. Our focus will be the basque Diaspora in Argentina during the last authoritarian government (1976-1983).
\end{abstract}

Keywords: Diaspora, civil society, dictatorship-immigration

\section{INTRODUCCIÓN}

En mayo de 2011, el gobierno de Estados Unidos convocó a un Foro de las Diásporas en su país, dirigido por la entonces Secretaria de Estado Hillary Clinton quien decía en su discurso de apertura:.. 'Vivimos en un mundo interconectado. La guerra está interconectada...la diplomacia está

\footnotetext{
${ }^{1}$ Magister en Relaciones Internacionales por la Universidad Nacional de La Plata (UNLP) Argentina y Doctora en Historia por la Universidad del País Vasco/Euskal Herriko Unibertsitatea (UPV/EHU) España. Mail: mcruset@hotmail.com
} 
interconectada...los negocios están interconectados...los medios están interconectados...la sociedad está interconectada...incluso la religión está interconectada. En este mundo el poder se mide por la conectividad"2

Es que, en un mundo cada vez más interconectado, todos quieren sacar provecho. Y así, en una relación costo-beneficio, la consigna es analizar las herramientas que hacen más eficiente a un grupo de emigrados para concretar sus objetivos.

En este trabajo intentamos justamente analizar este tema que entendemos como una interrelación entre características propias- liderazgo, número y compromiso de los miembros, asimilación a la sociedad de acogida, etc- y el contexto en el que se desenvuelven. Y, en este sentido, nos preguntamos que posibilidades de éxito pueden tener en situaciones límites de violencia y falta de libertad.

\section{DIÁSPORA Y SOCIEDAD CIVIL}

La palabra Diáspora - de origen griego, se refiere a la dispersión de la cultura greca en sus colonias - ha llegado a tener una enorme variedad de sentidos y a ser aplicada para designar diferentes grupos humanos en distintas situaciones históricas y contemporáneas. El Diccionario de la Real Academia Española lo define como la "Dispersión de grupos humanos que abandonan su lugar de origen" y, en una de las acepciones, la identifica expresamente con la "Dispersión de los judíos exiliados de su país". No obstante, casi cualquier pueblo desterritorializado, que se desplaza del centro a la periferia, puede ser admitido en esta categoría, que a veces se utiliza como alternativa a los conceptos de raza, nación y cultura. Además, el concepto permite acercarnos a la problemática de las identidades híbridas, que suelen ser desgarradoras y complejas, al intervenir dos lealtades distintas e incluso a veces antagónicas.

El geógrafo francés Bruneau sostiene que la Diáspora tiene tres características principales: 1) consciencia y reivindicación de una identidad propia, étnica o nacional; 2) existencia de una organización política, religiosa o cultural del grupo diaspórico (riqueza de la vida asociativa); 3 ) contactos reales o imaginarios con el país de origen. Según este autor, el individuo es parte de la

\footnotetext{
${ }^{2}$ http://www.state.gov/r/pa/prs/ps/2012/07/195375.htm tomado el 29 de noviembre de 2014.
} 
Diáspora por elección, por una decisión voluntaria y consciente. ${ }^{3}$ Para $\mathrm{Saffran}^{4}$, el término Diáspora debería aplicarse a aquellos expatriados que cumplen con algunas o varias de estas características:

1) Ellos o sus ancestros fueron dispersados de su lugar de origen.

2) Mantienen una memoria colectiva, imagen o mitos, de su "Home Land”- tanto el lugar físico, como histórico e ideológico.

3) No se sienten totalmente aceptados en el nuevo lugar de asentamiento.

4) Conservan el lugar de origen con intenciones de regresar algún día, ellos o sus descendientes.

5) Creen que de forma colectiva deben ser responsables de su lugar de origen.

6) Continúan relacionados de forma directa o de forma representativa, por solidaridad.

Hay autores, como Robert Brubaker, que prefieren hablar, más que de Diáspora, de "proyecto diaspórico", es decir, de un pueblo que tiene una práctica diaspórica para conseguir sus objetivos y no como una categoría independiente y solo forman parte de ella los individuos que se consideran parte de ese proyecto diaspórico. ${ }^{5}$

Desde el punto de vista cultural, el antropólogo Steven Vertovec y el sociólogo Robin Cohen utilizan el concepto de Diáspora para entender como se construyen las identidades globales desde las bases ("from below") y en movimiento ("on the move"). De acuerdo con estos autores hay que comprenderla desde tres aspectos: como forma social, como forma de conciencia y como forma de producción cultural. Esta sensación de "ser y no ser”, de “pertenecer y no pertenecer", del "acá y el allá", del anhelo del regreso que nunca llega, hace que el antropólogo estadounidense James Clifford ${ }^{6}$ describa estos procesos como de "pérdida y esperanza". Estas situaciones también se llevan al plano político y a las lealtades divididas entre el país de origen y el de acogida. Es por esto que el sujeto diaspórico crea una conciencia de sí mismo dual y paradójica, con un aspecto negativo que suele ser el prejuicio y desprecio en el nuevo lugar de arraigo; y otro positivo, a partir de su vinculación con una herencia histórica. Es por eso que sus narrativas continúan presentes a partir de la memoria, el mito, la fantasía. Y es por esta razón que, como historiadores, debemos acercarnos con cuidado a las fuentes

\footnotetext{
${ }^{3}$ BRUNEAU, M. “Espaces et territoires de diasporas”, en Diasporas. Montpellier, Reclus, 1995, pág. 8.

${ }^{4}$ SAFFRAN, William, Diasporas in Modern Societies: Myths of Homeland and Return , Diaspora: A Journal of Transnational Studies, Volume 1, Number 1, Spring 1991, p.84

${ }^{5}$ BRUBAKER, R. “The 'Diaspora’ Diaspora”, Ethnic and Racial Studies, 28, 2005, págs. 1-19.

${ }^{6}$ En ZUNTINI DE IZARRA, Laura Patricia. Narrativas de la diáspora irlandesa bajo la Cruz del Sur. Buenos Aires, Corregidor, 2010.
} 
que nos presentan un "Hogar nacional" sin tiempos, sin rivalidades y solo con conflictos que implican a enemigos exteriores.

Los nacionalismos identitarios se articulan fuertemente con sus Diásporas y acentúan el discurso de Madre Patria. Aquellos que han debido emigrar mantienen un vínculo estrecho con los familiares que aún quedan en el lugar de origen y una relación afectiva con el sitio que los vio nacer. Pronto, y de forma casi natural y espontánea, esos grupos buscan unirse como forma de mantener las costumbres y tradiciones. Con el tiempo van surgiendo lideres entre ellos que buscan un contacto más formal con el terruño dejado, generándose un mecanismo de retroalimentación y de ayuda mutua entre los “de acá” y los “de allá", y los intereses de ambos.

Desde el punto de vista de las Ciencias Políticas, hasta la década de 1960 este concepto era aplicado solo para tres grupos: los judíos, los armenios (a partir del siglo XI) y los griegos (hacia 1650). Con el comienzo de los fenómenos transnacionales y la globalización, el discurso de Diásporas fue adoptado en muchas otras disciplinas, haciendo el concepto mucho más flexible y adaptándolo a otras circunstancias. Estos grupos van adquiriendo poder, en términos de soft power, es decir, en su capacidad de influenciar a otros para lograr beneficios propios. Así reconocemos la habilidad que tienen sus elites de lograr contribuciones económicas, una especie de impuesto, de su propia comunidad; su capacidad para usar estos fondos para brindar servicios sociales, culturales o asistenciales que el Estado no les brinda; su efectividad, creando organizaciones propias que son capaces de actuar en la sociedad de acogida a través de su "poder económico", lobby político, representación en los medios, etc. Esto sucede incluso en aquellos casos donde los miembros del grupo nacionalista son elegidos al parlamento, o participan en la lucha armada.

Dentro de las actividades que pueden realizar estos grupos en los países receptores (donde muchas veces son ciudadanos), para involucrarlos a favor de sus "Madres Patrias", están en primer lugar el lobbying; en segundo lugar, su intento por influenciar los medios de comunicación, dando su propia visión sobre algún conflicto y tratando de poner de su parte a la sociedad civil. En tercer lugar, acudiendo a organizaciones supranacionales, como las Naciones Unidas o acudiendo a ONGs; por último, pueden tratar de influir a los gobernantes o elites de sus Home Lands.

Sea cual sea la definición de Diáspora que adoptemos queda claro que forman parte de la sociedad civil de los Estados-nación y dentro de este ámbito se mueven, cumpliendo con las premisas de accionar que tienen los demás segmentos,. Sin embargo, actúan a dos bandas, en dos sociedades civiles de forma simultánea. El éxito que tengan en lograr sus objetivos es una combinación de 
características internas como del contexto nacional- del Estado de origen y el de acogida-, como internacional.

\section{ESTADO Y SOCIEDAD CIVIL: EL DIFÍCIL EQUILIBRIO}

Desde finales del siglo XVII se desencadenan una serie de episodios revolucionarios que dan lugar a cartas constitucionales y declaraciones de derechos (Revolución Gloriosa en Inglaterra, 1688; declaración de la Independencia norteamericana, 1776; Revolución francesa, 1789; Declaración de los Derechos del Hombre, 1791) que instituyen al Estado sobre las bases de libertad, igualdad política, propiedad privada, etc. Los textos teóricos que dan marco ideológico a lo que nace son los clásicos Leviathan de Hobbes en 1651, los Dos tratados sobre el Gobierno de Locke, 1689 y el Contrato social de Rousseau en 1762.

El ciudadano renuncia a parte de sus derechos individuales en favor del Estado (Leviathan), que se convierte en un poder absoluto, consensuado y legitimado. Cuya función es defender los derechos fundamentales. Estos son según el ideario burgués, la seguridad, la libertad y el orden para Hobbes y la vida, la libertad y propiedad privada para Locke. De esta forma el Estado es una creación humana y legitima las formas de Monarquías Absolutas (Hobbes) o Parlamentarias (Locke). La propuesta de Rousseau avala la fórmula revolucionaria y republicana. Esto lo hace planteando la necesidad de un contrato social que garantice la igualdad (formal) de los hombres y la satisfacción de sus necesidades a través de un gobierno que ejecute la voluntad general del pueblo.

En la concepción clásica de Marx (1852), después desarrollada por Lenin, el Estado no es neutro, se vincula a la clase dominante y garantiza el proceso de dominación. Visiones más contemporáneas como las de Gramsci (1929) y Poutlanzas (1972) dan un enfoque un poco más complejo pero basado en los mismos principios. En el ala más izquierda de estos pensamientos teóricos clásicos, el anarquismo del siglo XIX, con Proudhom y Kropotkin, se plantean el modo de descentralizar y desconcentrar el poder que tiene el Estado.

La naciones, están constituidas por el concepto gramsciano del "complejo Estado/sociedad civil”. Mientras que para el nacionalismo civilista la variable Estado es la de mayor peso, pasa lo contrario con el nacionalismo romántico. Este marco teórico de análisis nos permitirá avanzar en el tema.

El concepto gramsciano del "complejo Estado/sociedad civil", que fue incorporado a la teoría de las relaciones internacionales por el norteamericano Robert W. Cox, nos recuerda que los diversos Estados están condicionados de muy diferentes maneras por sus respectivas sociedades civiles. De tal 
modo, visto en el largo plazo, el actor (o unidad) "nacional" que realmente interactúa en el orden interestatal con sus políticas exteriores no es simplemente el Estado, sino el complejo Estado/sociedad civil, que imprime a cada actor una lógica y una dinámica diferente a la de los demás actores o unidades.

Cada país registra una relación entre el Estado y la sociedad civil que le es propia y que lo diferencia de todos los demás. Sistemas políticos, estructuras sociales y culturas políticas determinan enormes diferencias en, por ejemplo, la medida en que el Estado puede imponerle sacrificios a la ciudadanía. También determinan diferencias significativas respecto a la mismísima definición de conceptos aparentemente universales como el de "interés", que se vuelve etnocéntrico en tanto la valoración de un mismo costo o beneficio cambiará en función de factores políticos, sociales y culturales que son particulares a cada sociedad civil y que tienen una fuerte incidencia sobre el Estado, ya sea por las presiones de la sociedad civil (el caso, digamos, de las verdaderas democracias), o porque la ausencia de presiones lo que genera una enorme autonomía al gobernante.

Por otra parte, incluso cuando la sociedad civil tiene un enorme peso sobre las decisiones del Estado, puede haber grandes diferencias cualitativas en el tipo de influencia que ésta ejerce debido a la intervención de variables culturales. La influencia de la sociedad civil sobre el Estado, por ejemplo, no siempre conduce a una administración más "racional" de la política exterior en términos del balance de costos y beneficios. Las estructuras sociales, los sistemas políticos y las culturas obran como condicionantes de primer orden en la percepción y valoración de hasta los parámetros más “objetivos".

El Estado receptor puede estar interesado en usar la agenda de cierta Diáspora en su propio beneficio. Por ejemplo, los cubanos exiliados en el fallido intento de invasión a Bahía Cochinos o - de forma más ventajosa- la participación de la administración Clinton en el Proceso de Paz de Irlanda del Norte. Lo que parece quedar claro es que, cuanto más democrática sea la sociedad en la que se participe, y no sólo en términos formales sino de acción cotidiana, más fácil le será hacer valer sus reclamos en política doméstica como desarrollar lobbys eficientes. Incluso insertándose en la estructura de los partidos políticos como forma de accionar.

La misma premisa puesta en sentido inverso también clarifica: cuanto menos democrática autoritaria, despótica, dictatorial-sea una sociedad, menor será el margen de maniobra de la sociedad civil, sometida a censura y represión. Sumado a la desconfianza que esta clase de regímenes tiene hacia lo asociativo en todos los niveles. La Diáspora, en estos casos, complejiza su situación por dos. Si el grado de democracia y, por lo tanto, el grado de libertad es bajo o nulo en los dos ámbitos en los que se mueven, fácilmente podemos entender que su viaje sea como el de Ulises, navegando entre Escila y 
Caribdis. Dos monstruos situados en orillas opuestas de un estrecho canal de agua, tan cerca que los marineros intentando evitar a Caribdis pasarían muy cerca de Escila y viceversa.

\section{ENTRE ESCILA Y CARIBDIS: EL MIEDO COMO VARIABLE}

Desde la llegada al país después de un largo exilio de Juan Domingo Perón el 20 de junio de 1973 en lo que se llamó la "Masacre de Ezeiza" - donde los sectores de derecha e izquierda dentro del mismo peronismo se atacaron mutuamente- quedaba claro que la Argentina estaba envuelta en una espiral de violencia muy difícil de contener y que, en la práctica, terminaría siendo frenada por el baño de sangre del terrorismo de Estado que ejerció la dictadura.

El 24 de marzo de 1976 es derrocada la Presidenta María Estela Martínez de Perón, por un golpe de Estado ejecutado por la Junta militar compuesta por el Teniente General José Rafael Videla, el Almirante Emilio Massera y el Brigadier Orlando Agosti. Tras siete años del auto proclamado "Proceso de reorganización nacional", el saldo fue una guerra con Inglaterra, un número grande de desaparecidos y exiliados ${ }^{7}$, la desarticulación de los sindicatos y partidos políticos, y la desmovilización de la sociedad civil.

Para la década de 1980 y para maquillar la situación interna vista en el exterior, los mismos miembros de la junta designan a Videla como Presidente del país. Es en este contexto de terrorismo de Estado y de fuerte censura en la prensa, que llegan las noticias de lo que ocurría en España, la vuelta a la democracia y la situación de violencia.

En la amordazada prensa local, donde pocas noticias son sobre asuntos domésticos y aún menos importantes, las que vienen del exterior son leídas en clave de "Guerra Fría". Así, se habla de los “terroristas" de Colombia, El Salvador e Italia. ${ }^{8}$ Por supuesto, del mismo modo, se habla de ETA y los frecuentes atentados en España. Esto no es raro, ya que esos primeros años de la década del 80 significaron una gran actividad del grupo formado unos veinte años antes como reacción a la dictadura de Franco.

\footnotetext{
${ }^{7}$ La comisión fue creada por Raúl Alfonsín el 15 de diciembre de 1983. Su misión fue la de recibir documentos y denuncias sobre las desapariciones, los secuestros y las torturas acontecidos dentro de aquel período a manos del régimen, y generar informes a partir de estos. El informe tuvo resultados satisfactorios, demostrando que la desaparición forzada de personas sí existió, y que no fueron casos aislados, pudiendo contar al menos 8961 personas que sufrieron esas atrocidades. La información sirvió como base del juicio a las Juntas de gobierno de la dictadura en 1985.

${ }^{8}$ Una excepción parece ser el IRA y los presos en huelga de hambre, a quienes se los suele nombrar como "activistas", "huelguistas" y muy pocas veces como terroristas.
} 
Se deja entrever que la Unión Soviética estaría detrás y que, por esta razón, España evaluaría sus relaciones diplomáticas. Del mismo modo buscaría ingresar al Tratado del Atlántico Norte como una forma de insertarse internacionalmente- después del largo aislamiento durante la dictadura- y, en cierto modo, de tomar partido. ${ }^{9}$

La visión sobre el grupo armado es muy negativa. Sus atentados se ven como de extrema violencia, amenazando el orden público y poniendo en peligro la nueva y frágil democracia española :" parecen empeñados en provocar a todo trance que una acción militar ponga fin al poder civil constitucionalmente establecido, en un esfuerzo por llevar su lucha al plano internacional..."10. De forma gráfica y sensacionalista se describen las consecuencias de los atentados. Un enviado especial de La Nación describe:

Una violencia impávida y fría, que no halla respuesta adecuada, prosigue su labor. El coche destrozado y restos informes, sangre sobre la calzada, tres transeúntes heridos de suma gravedad, nueve departamentos hechos añicos por la onda expansiva y la metralla, era lo que veían despavoridos los paseantes numerosos a esa hora en un día tibio de primavera ${ }^{11}$.

Lo que queda claro es que la prensa argentina pronto toma partido, poniendo epítetos de "terroristas", "suversivos", hasta "pistoleros". Se insiste en el financiamiento externo que tiene el grupo y se llega a plantear una especie de "internacional terrorista" mostrando una interconexión amplia. La Nación publica una extensa nota titulada "La Red del terror: los vínculos de la subversión", que comenta el capítulo X del libro de la periodista norteamericana Claire Sterling, que hace referencia a ETA. El mismo autor de la nota, reconoce que los datos que usa la autora, pueden estar manipulados por la CIA, pero igualmente considera que se les puede dar crédito. Refiere el entrenamiento que recibieron los vascos en Cuba por parte de un instructor soviético desde 1964 y como se trasladaron luego a Argelia, donde los instructores ahora eran cubanos y donde tomaron contacto con otras organizaciones subversivas como el IRA. Finaliza haciendo una referencia a una asamblea de terroristas en 1971, en el colegio de los Jesuitas en Florencia. ${ }^{12}$ Esta clase de comentarios no son neutros si se tiene en cuenta los seis jesuitas asesinados en El Salvador en 1989.

\footnotetext{
${ }^{9}$ El Día, 9 de marzo de 1981.

${ }^{10}$ El Día, 8 de mayo de 1981.

${ }^{11}$ La Nación, 6 de mayo de 1981.

${ }^{12}$ La Nación, 23 de abril de 1981.
} 
Y, en el discurso del régimen, de salvaguarda del occidente cristiano, se los describen como enemigos crueles y anticristianos. Por eso se acentúa cuando la víctima es un padre de familia- y familia numerosa-, miembro de las fuerzas de policía y, nada menos, que cuando éste salía de Misa:

Una mujer, miembro de las guerrillas vascas, dispuestas a destruir la democracia española, mató a tiros anoche a un coronel del ejército... La policía dijo que una mujer vasca disparó contra el Coronel Prieto, jefe de la policía provincial en Navarra durante 14 años, mientras entraba a la Iglesia de Nuestra Señora del Huerto con su esposa y varios de sus siete hijos. ...Su esposa e hija presenciaron su asesinato. ${ }^{13}$

Cuando los análisis son tendenciosos y superficiales; cuando de forma simplista se hace un alineamiento que en cierta forma no sólo es anti ETA y su violencia, sino también anti vascos, es fácil temer que algo de la sangre salpique también de este lado del océano. De poco sirven las declaraciones del Partido Nacionalista Vasco /PNV) desde Bilbao, hablando de una explotación de los sentimientos nacionalistas pero vaciándolos de contenido al tratar de instaurar un "Estado vasco marxista independiente", en un especie de "contrabando ideológico". ${ }^{14}$

\section{VASCOS DE ALLÁ Y DE ACÁ}

Aunque la inmigración vasca comenzó durante la colonia esta se hizo más constante a partir del siglo XIX. A partir de 1840 comenzó lo que algunos autores llaman la inmigración vasca temprana ${ }^{15}$, seguida por una mayor de 1870 a 1930, y una etapa final después de la Guerra Civil Española. Con la liberalización de los derechos de reunión de los extranjeros después de la batalla de Caseros (1852) comenzaron a fundarse los primeros centros comunitarios de españoles. En un primer momento los emigrantes vascos participaron de esos centros, aunque unos veinte años después ya comenzaron con los propios.

Marcelino Iriani, en su tesis sobre inmigración vasca a la Argentina, habla de unos 200.000 vascos que abandonaron la zona vasca entre 1840 y 1920, de ellos un 60\% se dirigió al Río de la Plata y la Pampa húmeda, lo cual significaría unas 60.000 personas

\footnotetext{
${ }^{13}$ El Día, 28 de marzo de 1981.

${ }^{14}$ La Nación, 18 de abril de 1981.

15 CAVIGLIA. Maria Jorgelina y VILLAR, Daniel. Inmigración vasca en Argentina.Departamento de Cultura del Gobierno Vasco.1994.
} 
ETA contaba con un apoyo discreto dentro de la Diáspora argentina. ${ }^{16}$. Pero este apoyo desaparece o se invisibiliza durante la dictadura. Era muy común en la época que las personas ocultaran material que pudiera ser considerado subversivo o directamente quemarlo por peligroso. Y esto podía incluir libros, como material del Peronismo e, incluso, algún material religioso más vinculado a la izquierda como las publicaciones del Padre Mujica.

La Federación de entidades vascas publica un comunicado como expresión del sentir sobre la situación:

La Federación de Entidades Vascas Argentinas (FEVA), integrada y respaldada por las instituciones representativas de la colectividad vasca en la República Argentina, desea expresar su más absoluto repudio a la acción violenta y terrorista que se vienen sucediendo en el País Vasco (Euzkadi).

Durante muchos años los vascos lucharon para recuperar sus libertades conculcadas , sufriendo por ello toda clase de persecuciones y vicisitudes. En esa lucha fueron acompañados por todos los hombres de bien que creían en la democracia, la libertad y la justicia, pero esto es otra cosa. ${ }^{17}$

Queda expresado que el apoyo a la causa vasca - a la cual no se le niega su justificación- se mantendrá en la medida que se continúen con los medios no violentos.

Lo que se nota en la prensa comunitaria es, por un lado, felicitarse por la salida electoral en el País Vasco; buscar con avidez información de lo que realmente está ocurriendo en cuanto a la violencia, tratar de mostrar una imagen distinta del vasco y condenar el terrorismo.

De este modo, La Baskonia - la tradicional publicación vasca, que se fundó el 10 de octubre de 1893 y se publicó hasta 1943 retomando en 1978 de forma irregular hasta la década de 1980. A esta última etapa se la llamó "segunda época" - trata de buscar información de lo que realmente está pasando en Euskadi. Así se entrevistan a personas que vienen de allá o han estado circunstancialmente buscando referencias más allá de la prensa local. La entrevista al Padre José María Aguiirebalzategui, es particularmente interesante. Lo primero que destaca es la simplista asimilación entre vasco y etarra que existía en la sociedad. Él mismo lo cuenta: "El primero, aquí, que me preguntó sobre esto lo hizo con bastante mala saña. Me preguntó si todos éramos de la ETA.” Pero, lo curiosa es la respuesta que da, curiosa por lo reflexionada que estaba, preparada y poco espontánea.

¿Sabe Ud. que dos mil hombres durmiendo, aunque estén roncando, meten menos ruido que dos borrachos cantando en la calle? Lo malo, es que esos hombres sigan dormidos y no hagan callar a los otros o nos los convenzan. ${ }^{18}$

\footnotetext{
${ }^{16}$ Desde 1969 a 1975 se publicaba en Lomas de Zamora (provincia de Buenos Aires), el periódico Euzko Abertzale Laguntza, que se ocupaba de apoyar de a los presos políticos vascos.

17 IRINTZI, diciembre de 1980.

${ }^{18}$ La Baskonia, Mayo-junio de 1980.
} 
Todo esto para terminar con un lapidario:” El pueblo basko es pacífico". ${ }^{19}$

También para estas fechas se hace referencia a un informe realizado sobre el estado de situación de los Centros Vascos. Entre los ítems que se evalúan está la falta de difusión de los temas vascos en los medios . Esto más sentido al no aprovechar los 400 años de la segunda fundación de la ciudad de Buenos Aires- que concitaba toda clase de actos y homenajes en esas fechas- por el vasco Juan de Garay que, aunque no se puede certificar fehacientemente su origen, funciona como una especie de "mito fundacional" en la colectividad. Cuando comienzan a indagar en la razón de tal situación queda claro: ..."se debe al temor de muchos de verse identificados con temas de violencia en extramuros". ${ }^{20}$

\section{CONCLUSIÓN}

Entendemos que el éxito de las Diásporas a la hora de obtener sus objetivos, está determinado por características propias y la coyuntura en la que actúan. Como parte de la sociedad civil están en un delicado equilibrio con el Estado y lo que éste le permite. Cuanto más democrático sea un país, más permeable será a la actividad directa de los ciudadanos. Es ente contexto donde las Diásporas más organizadas consiguen sus mayores logros.

Por el contrario, los regímenes totalitarios desarticulan toda acción de la sociedad civil, casi como una definición de lo que implican estos sistemas de Estados todopoderosos. Es en estos casos, donde la represión es la metodología de control - a partir de un terrorismo desde el mismo Estadodonde "invernar" no es sólo la única alternativa posible, sino la más sabia en términos de costebeneficio.

\section{BIBILOGRAFIA}

BRUBAKER, R. “The 'Diaspora’ Diaspora”, Ethnic and Racial Studies, 28, 2005, págs. 1-19. BRUNEAU, M. "Espaces et territoires de diasporas”, en Diasporas. Montpellier, Reclus, 1995, pág. 8.

CAVIGLIA. Maria Jorgelina y VILLAR, Daniel. Inmigración vasca en Argentina. Departamento de Cultura del Gobierno Vasco.1994.

\footnotetext{
${ }^{19} \mathrm{LB}$, idem.

${ }^{20}$ LB, Marzo-abril 1980
} 
Quaestio Iuris

SAFFRAN, William, Diasporas in Modern Societies: Myths of Homeland and Return, Diaspora: A Journal of Transnational Studies, Volume 1, Number 1, Spring 1991, p.84

ZUNTINI DE IZARRA, Laura Patricia. Narrativas de la diáspora irlandesa bajo la Cruz del Sur. Buenos Aires, Corregidor, 2010.

Trabalho recebido em 17 de dezembro de 2014 Aceito em 31 de outubro de 2021 